\title{
Estimation of the efficiency of synthetic fertilizers in intensifying agricultural production
}

\author{
Andrey Gusev* \\ Ryazan State Agrotechnological University Named after P.A. Kostychev, 390044 Ryazan, Russia
}

\begin{abstract}
Sustainable growth in agricultural production should be based on the processes of intensification of agricultural production. Unfortunately, the concept of "intensification" has been forgotten in the post-reform period, but the processes taking place in the industry indicate the opposite. Practice shows that many elements and signs of intensification are present to a greater extent in a market economy. Modern agricultural production is based on a farming system, a component of which is a system of mineral nutrition for agricultural crops. Chemicalization, as an element of intensification, is a key factor in increasing yields, profit and profitability of production. Significant financial resources of enterprises are invested into this direction. The peculiarity of the current level of development of the industry is that the prospects for the development of crop raising should be focused on optimizing the proportions of mineral nutrition that do not violate the natural and ecological balance, which implies the cultivation of ecologically clean agricultural products. It is proposed to assess the effectiveness of the chemicalization process by the coefficient (indicator) of the level of return of mineral fertilizers by agricultural products.
\end{abstract}

\section{Introduction}

Stable growth in crop yields, and as a consequence, growth in agricultural production, are closely related to intensification of agricultural production and the system of mineral nutrition being its component. The economic efficiency of agricultural production, profitability, return and other economic parameters depend on the yield per unit of land area. Modern agricultural production cannot be imagined without this key element of the farming system. When optimal and scientifically grounded rates of mineral fertilization, a stable increase in crop yields occurs. Excessive application sometimes leads to a decrease in yields and, most importantly, a loss of product quality. The problems of assessing the economic efficiency of intensification in a market economy, and its correlation with the process of chemicalization of the agricultural sector are covered rather poorly or practically absent in modern scientific literature.

In modern science, there are various methods and techniques for assessing the economic efficiency of using fertilizers but, as a rule, they are outdated for a long time, therefore this

\footnotetext{
*Corresponding author: ay.gusev@mail.ru
} 
problem remains very relevant, since the practical activity of the industry in the field of the using synthetic fertilizers in the production of agricultural products dictates the need to update old methods and techniques for scientific research in this area, or develop new ones, taking into account the changing production conditions in the direction of their adaptation to real time. Therefore, it is proposed to evaluate the efficiency of the mineral nutrition system according to the parameter (coefficient) of the level of return of mineral fertilizers by agricultural products, which will allow working out correct and effective approaches to the further development of intensification processes in the industry. Problems and prospects for the development of intensification in the agrarian sphere of the national economies of many countries are touched upon in a number of works by foreign and Russian scientists, which indicates the many aspects of the scientific direction. Thus, the processes of intensification and its consequences, in particular, the issues of environmental safety are reflected in [1], where the author raises the problem of promoting renewable energy sources, protecting against water pollution and preserving soil fertility. Russian scientists substantiate the need to intensify production by the growth of the population and, as a consequence, the increasing need in food, proving the need to use artificial intelligence in agriculture to solve tasks set for the industry [2]. Some authors [3] consider the processes of intensification as a solution to the problem of import substitution, identifying the constraining factors for the development of regions and intensification of the key points of economic growth. The negative consequences of intensification are highlighted in the work [4], where, using the example of Vietnam, the need to change the practice of farming and the use of "smart" intensification, considering scientifically based sowing cycles, is proved. The work [5] is devoted to negative consequences of intensification of agricultural production.

The problems of mega deltas are considered and proposals are made for assessing the risks and their leveling as a result of intensification. The necessity and indispensability of synthetic fertilizers in the foreseeable future is substantiated in a scientific study [6], where the authors prove the main ecological advantage of legumes as a substitute for animal products, but not a way to reduce the need for mineral fertilizers. Other researchers substantiate the need for an intensification process through the large-scale use of synthetic fertilizers and means of protection against pests and diseases, linking this process with an increase in grain yield and maintenance of soil fertility [7]. Our research also confirms the validity and irreversibility of intensification processes in the agrarian sector of the national economy and the system of using synthetic fertilizers, being an integral element [8-10]. The negative consequences of intensification in agriculture from the standpoint of social consequences are considered by a number of authors [11] arguing that modernization and intensification lead to a decrease in the level of employment in the industry. Modern agricultural production focuses on innovative approaches to this direction.

Thus, the innovation processes taking place in the agro-industrial complex should be combined, from our point of view, with the processes of intensification of agricultural production, since their main and common goal is to increase the efficiency (effectiveness) of production. It is known that the introduction of synthetic fertilizers into the soil significantly affects the ecosystem. Today this problem is urgent, because there is an increase in the production of synthetic fertilizers in the country, thus the stake is placed on their use in the production of agricultural products, therefore there is a real problem associated with the violation of the ecological balance in nature. In order to avoid an ecological catastrophe, this process should be oriented towards the optimal application of such fertilizers, which consists in achieving high yields of agricultural crops without disturbing the ecological situation, ecological balance in nature. Otherwise alternative ways of increasing the productivity of fields and farms should be sought, but today the prospects for the development of the crop production and the growth of crop yields, both in the 
country as a whole and at the regional level, are seen in the development of methods and techniques for introducing optimal rates of synthetic fertilizers that do not violate the natural and ecological balance.

\section{Materials and methods}

The process of intensifying the industry has a multifaceted nature, the study of which should be based on scientific techniques and research methods. When writing the work, a variety of research methods was used: monographic, analytical, economic and statistical, the method of a systematic approach to the study of economic phenomena, which made it possible to conduct an objective and independent assessment of the efficiency of synthetic fertilizers. The course towards the use of synthetic fertilizers is caused by the fact that in recent years there has been an acute shortage of organic fertilizers in the industry, therefore, many agricultural enterprises cover the needs for organic matter with ever-increasing specific volumes of mineral fertilizers per unit of land area. It is known that organic fertilizers provide high yields and environmentally friendly agricultural products without harming human health. Today, there is no possibility of introducing the necessary norms of organic fertilizers on the existing areas occupied by agricultural crops in the agricultural sector of either Ryazan region or the whole country.

So, according to statistical bodies, the share of agricultural land with applied organic fertilizers in the region averages only $2.1 \%$ for the study period, which is a too low indicator and cannot have a significant effect on the growth of productivity, give a significant production increase of environmentally friendly products. So, the largest share of the introduced organic matter in the region falls on potatoes $-4 \mathrm{t} / \mathrm{ha}$, grain and legumes $0.7 \mathrm{t} / \mathrm{ha}$ and fodder crops $-1.1 \mathrm{t} / \mathrm{ha}$, but such rates of fertilization are very modest. The practical experience of many agricultural enterprises confirms that the process of intensification of agricultural production is irreversible and due to the lack of organic fertilizers, synthetic fertilizers should play a key role in increasing crop yields. The majority of agricultural enterprises are guided precisely by such a policy in the agricultural sector, as evidenced by the regional indicators of the dynamics of the application of mineral fertilizers for the period of 2013-2018 (Table 1).

Table 1. Dynamics of indicators of the level of mineral fertilizers application for agricultural crops of the regional agro-industrial complex.

\begin{tabular}{|c|c|c|c|c|c|c|c|c|}
\hline Parameters & 2013 & 2014 & 2015 & 2016 & 2017 & 2018 & \multicolumn{2}{|c|}{ Deviation } \\
\cline { 3 - 9 } & & & & & & & $\begin{array}{c}\text { in absolute } \\
\text { terms (-/+) }\end{array}$ & $\begin{array}{c}\text { in } \\
\text { relative } \\
\text { terms, \% }\end{array}$ \\
\hline $\begin{array}{c}\text { Mineral fertilizers } \\
\text { applied for } \\
\text { agricultural crops } \\
\text { (in terms of 100\% } \\
\text { nutrients), total, } \\
\text { thousand tons }\end{array}$ & 36.2 & 36.3 & 39.5 & 45.2 & 48.3 & 56.1 & +19.9 & +54.9 \\
\hline $\begin{array}{c}\text { per 1 ha of the } \\
\text { entire sown area, kg }\end{array}$ & 51 & 53 & 55 & 63 & 73 & 74 & +23 & +45.1 \\
\hline $\begin{array}{c}\text { Change index } \\
\text { including cereals } \\
\text { and legumes } \\
\text { (without corn) }\end{array}$ & 1.00 & 1.04 & 1.08 & 1.24 & 1.43 & 1.45 & - & - \\
\hline sugar beet & 288 & 55 & 57 & 64 & 75 & 76 & +25 & +49.0 \\
\hline sunflower & 59 & 51 & 315 & 206 & 398 & 282 & -6 & -2 \\
\hline $\begin{array}{c}\text { vegetables and } \\
\text { cucurbits }\end{array}$ & 79 & 88 & 111 & 164 & 222 & 197 & +118 & 1.5 times \\
\hline potatoes & 281 & 217 & 308 & 302 & 263 & 264 & -17 & -6.0 \\
\hline
\end{tabular}




\begin{tabular}{|c|c|c|c|c|c|c|c|c|}
\hline forage crops & 26 & 30 & 29 & 34 & 38 & 49 & +23 & +88.4 \\
\hline $\begin{array}{c}\text { Specific area with } \\
\text { applied mineral } \\
\text { fertilizers in the } \\
\text { entire sown area, \% }\end{array}$ & 72 & 72 & 71 & 78 & 82 & 81 & - & +9.0 \\
\hline
\end{tabular}

There is a systemic increase in the volume of synthetic fertilizers applied to the main agricultural crops. So, during the study period in the region, the application of mineral fertilizers for agricultural crops (in terms of 100\% nutrients) increased by 19.9 thousand tons or $54.9 \%$, and by $23 \mathrm{~kg}$ or by $45.1 \%$ per hectare of sown area. Most of the fertilizers were applied for fodder, grain and legumes, which indicates the current stable trend aimed at increasing the level of intensification of agricultural production through the mineral nutrition system, which should result in an increase in production volumes. Studies of the tightness of the correlation between the yield and the size of the applied mineral fertilizers is very high, which means that the yield is largely determined by the mineral nutrition system. Therefore, the ever-increasing volumes of applied synthetic fertilizers can negatively affect the quality of the products, since chemical elements and compounds harmful to human health accumulate in it. Due to the fact that many crop growing products are directly or indirectly consumed by humans for food, it is likely that a threat to health will arise. Therefore, at the present stage of development of this direction of intensification, the key task is to optimize the rates of application of synthetic fertilizers, both in volume and in the ratio of NPK (nitrogen, phosphorus, potassium), considering the optimal need for plants, soil characteristics, and the growth characteristics of each agricultural crop in a specific natural and climatic zone. Taking these factors into account should contribute to a stable increase in yield, compliance with the requirements for environmental cleanness of products, and a reduction in risks associated with human health. Let's analyze the effectiveness of the intensification process in terms of the dynamics of the yield of the main crops growing in the region (Table 2).

Table 2. Dynamics of productivity indicators of agricultural crops in the region, $\mathrm{dt} / \mathrm{ha}$.

\begin{tabular}{|c|c|c|c|c|c|c|c|c|}
\hline \multirow[t]{2}{*}{ Parameters } & \multirow[t]{2}{*}{2013} & \multirow[t]{2}{*}{2014} & \multirow[t]{2}{*}{2015} & \multirow[t]{2}{*}{2016} & \multirow[t]{2}{*}{2017} & \multirow[t]{2}{*}{2018} & \multicolumn{2}{|c|}{ Changes to 2013} \\
\hline & & & & & & & $\begin{array}{l}\text { in absolute } \\
\text { terms, dt/ha } \\
(-/+)\end{array}$ & $\begin{array}{c}\text { in } \\
\text { relative } \\
\text { terms, } \\
\%\end{array}$ \\
\hline $\begin{array}{c}\text { Cereals } \\
\text { (weight after } \\
\text { processing) }\end{array}$ & 25.9 & 29.8 & 30.2 & 29.4 & 36.2 & 28.6 & +2.7 & +10.4 \\
\hline Change index & 1.00 & 1.15 & 1.16 & 1.14 & 1.39 & 1.10 & - & - \\
\hline Sugar beet & 409.5 & 321.4 & 429.0 & 488.8 & 463.4 & 385.7 & -23.8 & -5.8 \\
\hline Change index & 1.00 & 0.78 & 1.04 & 1.19 & 1.13 & 0.94 & - & - \\
\hline Potatoes & 146.3 & 142.5 & 175.3 & 155.2 & 155.7 & 148.5 & +2.2 & +1.5 \\
\hline Change index & 1.00 & 0.97 & 1.19 & 1.06 & 1.06 & 1.01 & - & - \\
\hline $\begin{array}{c}\text { Field } \\
\text { vegetables }\end{array}$ & 143.4 & 153.4 & 157.8 & 162.0 & 154.5 & 154.7 & +11.3 & +7.8 \\
\hline Change index & 1.00 & 1.07 & 1.09 & 1.13 & 1.07 & 1.07 & - & - \\
\hline $\begin{array}{c}\text { Fruits and } \\
\text { berries }\end{array}$ & 52.7 & 56.4 & 66.8 & 61.6 & 47.9 & 66.4 & +13.7 & +25.9 \\
\hline Change index & 1.00 & 1.07 & 1.27 & 1.17 & 0.91 & 1.26 & - & - \\
\hline
\end{tabular}

According to the table, there is a positive trend in the growth of agricultural yields in relative and absolute terms, but the yield increased very slightly in absolute terms, which indicates a low effect (result) of intensification of production, manifested primarily through the main factor in the growth of agricultural land productivity, i.e. a system of mineral nutrition. 


\section{Results and discussion}

It is possible to assess the effectiveness (efficiency) of the mineral nutrition system by the level of return of mineral fertilizers by agricultural products, which can be calculated as the ratio of the yield of crop production in centners per hectare of agricultural land (arable land) to the amount of fertilizers applied, in terms of $100 \%$ of nutrients, per unit of land area. As a result of calculating such a ratio, an indicator less than one will characterize a low level of intensification efficiency, and a parameter above one will demonstrate a higher efficiency of this process, which will allow agricultural specialists to take the most effective and efficient measures aimed at leveling the negative impact of synthetic fertilizers and determine other prior directions of intensification of agricultural production. The results of such a study lead to understanding the need to suspend the use of synthetic fertilizers in the industry, because further expenditure of monetary resources in this direction will be ineffective, increasing the cost of manufactured products, reducing profit and profitability. Studying this indicator in a dynamic series will allow researchers to analyze changes in yield, its relationship with the mineral nutrition system in time and space, and consequently to make effective decisions based on the results. It is likely that the yield of agricultural crops is influenced by a complex of factors, both dependent and not dependent on human activity, for example, weather conditions. Therefore, it is likely that the manufacturer cannot influence this, but there are other factors that directly depend on human activities, for example, an effective farming system adapted to local conditions, and an integral part of this system - an effective technology for the production of a specific type of product, an effective system of machines serving the technological process and many other components of the system, and, of course, a fertilizer system. Therefore, a deep study of the influence of this parameter on productivity is quite natural and justified. The payback of synthetic fertilizers will be calculated by crop production using its main types for the region. The effectiveness of their introduction will be determined through the proposed indicator (parameter) for assessing the payback (Table 3).

Table 3. The payback level of the applied synthetic fertilizers by crops.

\begin{tabular}{|c|c|c|c|c|c|c|c|}
\hline Parameters & 2013 & 2014 & 2015 & 2016 & 2017 & 2018 & $\begin{array}{c}\text { Change for the } \\
\text { period to the level } \\
\text { of 2013, } \%\end{array}$ \\
\hline $\begin{array}{c}\text { Payback by } \\
\text { cereals }\end{array}$ & 0.51 & 0.56 & 0.55 & 0.47 & 0.50 & 0.38 & 76.0 \\
\hline $\begin{array}{c}\text { Payback by sugar } \\
\text { beet }\end{array}$ & 1.42 & 2.21 & 1.36 & 2.37 & 1.16 & 1.37 & 96.4 \\
\hline $\begin{array}{c}\text { Payback by } \\
\text { potatoes }\end{array}$ & 0.52 & 0.65 & 0.57 & 0.51 & 0.59 & 0.56 & 107.7 \\
\hline $\begin{array}{c}\text { Payback by } \\
\text { vegetables and } \\
\text { cucurbits }\end{array}$ & 1.81 & 1.74 & 1.42 & 0.99 & 0.70 & 0.79 & 43.6 \\
\hline
\end{tabular}

The studied parameters of the payback of fertilizers by crop products allow to conclude that the efficiency of fertilization for most types of cultivated crops decreases every year. In 2018 , the most significant decrease in the payback of fertilizers was shown by vegetables and cucurbits (43.6\% compared to the level of 2013), thus, the efficiency of mineral fertilization decreased by $56.4 \%$. A negative trend is also characterized by the payback rates of sugar beet $-96.4 \%$, although the payback rate was higher than 1 and that of grain $76 \%$. Potatoes turned out to be slightly more responsive to fertilizers and its payback increased by $7.7 \%$, but such an increase in payback over a six-year period cannot seem to be sufficient to recognize the results of the work of the potato industry in the region as effective. 
Let's carry out an analytical decomposition of the proposed payback parameter into a complex of factors influencing it, in order to find out the reasons for its change in time and the level of influence of each factor. For example, according to previous calculations, there is a steady decline in the payback rate for such key crops cultivated in the region as cereals and legumes, where it is necessary to find out the reasons leading to a decrease in the payback of synthetic fertilizers by increasing yields (Table 4).

Table 4. Analytical assessment of the payback of fertilizers by grain crops.

\begin{tabular}{|c|c|c|c|}
\hline Parameters & 2013 & 2018 & Parameter deviation \\
\hline $\begin{array}{c}\text { Mineral fertilizers applied for cereals and } \\
\text { legumes, } \mathrm{kg} / \mathrm{ha}\end{array}$ & 51.0 & 74.0 & +23.0 \\
\hline Cereals yield in the region, dt/ha & 25.9 & 28.6 & +2.7 \\
\hline Payback of fertilizers by increase in production & 0.51 & 0.38 & -0.13 \\
\hline Relative payback & \multicolumn{3}{|c|}{0.56} \\
\hline $\begin{array}{c}\text { Impact of parameter "yield of grain and legumes" } \\
\text { on the payback of mineral fertilizers }\end{array}$ & \multicolumn{3}{|c|}{$0.56-0.51=+0.05$} \\
\hline $\begin{array}{c}\text { Influence of parameter "the amount of applied } \\
\text { fertilizers per unit of land area" on the payback of } \\
\text { mineral fertilizers }\end{array}$ & \multicolumn{3}{|c|}{$0.56=-0.18$} \\
\hline Correlation identifier & $0.05+(-0.18)=-0.13$ \\
\hline
\end{tabular}

Thus, an increase in the rates of application of synthetic fertilizers does not stimulate the necessary increase in the yield of grain crops. Additional application leads to a decrease in the payback of fertilizers by 0.18 p.p. and the degree of increase in yield is only 0.05 p.p. Therefore, the subsequent specific application of synthetic fertilization per unit of area occupied by grain and legumes is ineffective and does not lead to an increase in yield. In this case, it is necessary to look for other ways to increase productivity. This analytical assessment of the payback of fertilizers by major crops growing in the region made it possible to form a matrix of the payback of fertilizers by crops (Table 5).

Table 5. Matrix for assessing the investment return of synthetic fertilizers by crops.

\begin{tabular}{|c|c|c|c|}
\hline Crop & \multirow{2}{*}{$\begin{array}{c}\text { The } \\
\text { cumulative } \\
\text { influence of } \\
\text { factors }\end{array}$} & \multicolumn{2}{|c|}{ including the influence of the parameter } \\
\cline { 3 - 4 } & -0.13 & +0.05 & -0.18 \\
\hline $\begin{array}{c}\text { Cereals and } \\
\text { legumes }\end{array}$ & & -0.08 & +0.03 \\
\hline Sugar beet & -0.05 & 0.00 & +0.04 \\
\hline Potatoes & +0.04 & +0.15 & -1.17 \\
\hline $\begin{array}{c}\text { Vegetables } \\
\text { and cucurbits }\end{array}$ & -1.02 & & "Specific weight of applied synthetic \\
\hline
\end{tabular}

The presented calculations confirm the statement that synthetic fertilizers are used ineffectively in the region. So, the payback of synthetic fertilizers by vegetables and cucurbits in 2018 decreases by 1.17 p.p., although significant specific volumes were introduced for these crops being 1.5 times higher than the rates of their application in the base period (2013), which made it possible to achieve only 0.15 p.p. increase in yield. The negative influence of the factor can be traced in cereals and legumes. For other crops, the payback indicators are also at a low level, therefore, in the current situation for the region, this direction of intensification of agro-industrial production is ineffective. 


\section{Conclusion}

Thus, one of the key areas of intensification of the industry was studied, namely, the chemicalization process, and an algorithm for assessing the economic efficiency of the use of synthetic fertilizers was proposed. On the basis of this method, an objective study of the current level of efficiency of using such fertilizers was carried out, the shortcomings and "bottlenecks" of this process were identified. Conclusions were drawn about its inefficiency in modern production conditions and the points of further growth of the results of economic activities of agricultural enterprises were determined, based on new approaches to the process of intensification.

The research shows that an increase in the rates of application of synthetic fertilizers per unit of land area does not stimulate an increase in the yield of agricultural crops growing in the region. The ratio of the indicators presented in the analytical matrix proves their ineffective use, which requires a close study and objective assessment of the farming system that has developed in the region, as well as the urgent development of new approaches to its application, focusing on a more progressive scientifically based system of mineral nutrition, adapted to the existing climatic and soil conditions of agricultural crops. Otherwise, the investment in the chemicalization process may have a prolonged negative result, since prices for modern, both simple and complex synthetic fertilizers are very high and have a stable tendency to increase, and their costs are an essential component of the cost of agricultural products not only in the crop growing industry, but also in animal husbandry, manifesting themselves through feed and having a direct impact on the cost of meat and milk.

The proposed algorithm for assessing the effectiveness of one of the intensification directions can be applied in a practical plane by specialists in the agro-industrial complex for an objective and comprehensive assessment of the effectiveness of the intensification process in the crop production industry in order to develop effective measures to increase profits (income), considering the specific features of the mineral nutrition system and search, if necessary, other alternative and less costly approaches in the work of the industry.

\section{References}

1. S. Silva, A.C. Rodrigues, A. Ferraz, J. Alonso, Waste Biomass Management - A Holistic Approach (Springer, 2017)

2. G.V. Fedotova, R.H. Ilyasov, N.E. Buletova, T.A. Yakushkina, T.K. Kurbanov, AISC, 1100 (2020)

3. E. Cherkesova, D. Mironova, I. Slatvitskaya, L. Simonyan, IOP Conference Series: Earth and Environmental Sci. 403(1), 012040 (2019)

4. D.D. Tran, L.H. Huu, L.P. Hoang, T.D. Pham, A.H. Nguyen, Agricultural Water Management, 243, 106495 (2021)

5. C. Kuenzer, V. Heimhuber, J. Day, T. Schlurmann, W. Glamore, Ocean and Coastal Management, 198, 105362 (2020)

6. R. Prudhomme, T. Brunelle, P. Dumas, A. Le Moing, X. Zhang, Regional Environmental Change, 20(3), 91 (2020)

7. O. Makarova, V. Makarov, S. Gasparyan, Z. Napris, A. Shemyakin, E3S Web of Conferences, 175, 01003 (2020)

8. E. Metelkova, G. Demishkevich, A. Gusev, IOP Conf. Series: Earth and Environmental Science, 274 (2019) 
9. A.Yu. Gusev, T.A. Sycheva, A.A. Romanov, Agricultural Economics of Russia, 2, 8 (2019)

10. A.Yu. Gusev, T.A. Sycheva, Agricultural Economics of Russia, 7, 21 (2018)

11. Yu.N. Nikulina, V.N. Surovtsev, Agricultural Economics of Russia, 2, 9 (2020) 